[Article]

\title{
大面积全柔性染料敏化太阳能电池光电性能优化
}

\author{
林逍武明星安江 苗青青 覃达 马廷丽” \\ (大连理工大学化工学院精细化工国家重点实验室, 辽宁大连 116024)
}

摘要: 设计并制作了大面积高效全柔性染料敏化太阳能电池(DSCs). 通过引入光散射层或施加机械压力, DSCs 的光电转化效率有了大幅度提高. 实验室小面积 $(0.4 \mathrm{~cm} \times 0.4 \mathrm{~cm})$ 柔性 DSCs 的光电转化效率达到 $5.50 \%$. 大面积 $\left(2 \mathrm{~cm} \times 3 \mathrm{~cm}\right.$, 活性面积为 $\left.2.7 \mathrm{~cm}^{2}\right)$ DSCs 的光电转化效率从未进行处理的 $1.52 \%$ 上升到 $1.81 \%$ 和 $2.50 \%$, 分别提高了 $20.0 \%$ 和 $66.7 \% .5 \mathrm{~cm} \times 7 \mathrm{~cm}$ 面积的 DSCs (活性面积为 $16.2 \mathrm{~cm}^{2}$ ) 的光电转化效率在未 做任何优化处理的条件下达到了 $1.60 \%$ (光强 $40 \mathrm{~mW} \cdot \mathrm{cm}^{-2}$ ). 同时, 本文对提高光电转化效率的机理进行了深 入研究. 电化学阻抗测试结果表明, 加压法能明显减小电池的内部串联电阻 $\left(R_{\mathrm{s}}\right)$ 及 $\mathrm{TiO}_{2} /$ 染料/电解液界面间的传 荷电阻 $\left(R_{\mathrm{ct}}\right)$. 扫描电镜结果也显示加压后 $\mathrm{TiO}_{2}$ 粒子之间粘结更加紧密, 更利于电子在 $\mathrm{TiO}_{2}$ 薄膜中的传输及染料 的吸附. 另外, $900 \mathrm{~h}$ 的长期稳定性实验结果表明, 制作的柔性 DSCs 的各项光电性能参数均无明显下降. 该实 验结果为柔性染料敏化太阳能电池的基础研究和大面积产业化技术研究奠定了基础.

关键词：全柔性；太阳能电池；散射层；加压法；稳定性

中图分类号: 0644

\section{Optimization of the Photoelectric Performance of Large-Scale All-Flexible Dye-Sensitized Solar Cells}

\author{
LIN Xiao WU Ming-Xing AN Jiang MIAO Qing-Qing Q QIN Da MA Ting-Li* \\ (State Key Laboratory of Fine Chemicals, School of Chemical Engineering, Dalian University of Technology, \\ Dalian 116024, Liaoning Province, P. R. China)
}

\begin{abstract}
Highly efficient large scale flexible dye-sensitized solar cells (DSCs) were successfully designed and fabricated. By the introduction of a light scattering layer or pressure, the DSC efficiency was greatly improved. The flexible DSCs with a small surface area $(0.4 \mathrm{~cm} \times 0.4 \mathrm{~cm})$ gave a high energy conversion efficiency of 5.50\%. The energy conversion efficiencies of large area DSCs $(2 \mathrm{~cm} \times 3 \mathrm{~cm}$, active area of $2.7 \mathrm{~cm}^{2}$ ) improved from $1.52 \%$ to $1.81 \%$ and $2.50 \%$, which is an increase of $20.0 \%$ and $66.7 \%$ compared with the DSCs prepared without any treatment. The $5 \mathrm{~cm} \times 7 \mathrm{~cm}$ DSCs (active area of $16.2 \mathrm{~cm}^{2}$ ) without any optimization showed an energy conversion efficiency of $1.60 \%$ under a sunlight intensity of 40 $\mathrm{mW} \cdot \mathrm{cm}^{-2}$. The mechanism for the improvement in efficiency was also studied. The results of electrochemical impedance spectroscopy (EIS) demonstrated that the pressure method can significantly reduce the series resistance $\left(R_{\mathrm{s}}\right)$ and the charge transfer resistance $\left(R_{\mathrm{ct}}\right)$ in the $\mathrm{TiO}_{2} /$ dye/electrolyte interface. Scanning electron microscopy (SEM) showed that the $\mathrm{TiO}_{2}$ particles were far more closely connected after pressing, which was helpful for electron transport in the $\mathrm{TiO}_{2}$ network as well as for dye adsorption. In addition, the photovoltaic parameters of these flexible DSCs were found to be stable after the $900 \mathrm{~h}$ stability tests. The experimental results obtained for these flexible DSCs can be used as a foundation for further basic research and for industrialization technical research.
\end{abstract}

Received: July 4, 2011; Revised: August 26, 2011; Published on Web: September 2, 2011.

"Corresponding author. Email: tinglima@dlut.edu.cn; Tel: +86-411-84986237.

The project was supported by the National Natural Science Foundation of China (50773008) and National High Technology Research and Development Program of China (863) (2009AA03Z220).

国家自然科学基金(50773008)及国家高技术研究发展计划(863) (2009AA03Z220)资助项目

(C) Editorial office of Acta Physico-Chimica Sinica 
Key Words: All-flexibility; Solar cell; Scattering layer; Pressure method; Stability

\section{1 引言}

自 1991 年染料敏化太阳能电池(DSCs)被首次 报道以来, ${ }^{1}$ 由于其制作工艺简单、成本低、无污染、 具有较高的光电转化效率等优点引起广泛关注. ${ }^{2-5}$ DSCs 通常是由吸附染料的纳米多孔 $\mathrm{TiO}_{2}$ 薄膜、带 有 $\mathrm{Pt}$ 的对电极以及含有 $\mathrm{I}_{3}^{-} / \mathrm{I}^{-}$氧化还原电对的电解液 所组成. 传统的刚性 DSCs 以镀有铟锡金属氧化物 (ITO)导电层的玻璃为电极基板, 存在着易碎、质重、 可塑性差、不易加工等缺点. 2000 年, Pichot 研究组 ${ }^{6}$ 发表了以高分子导电膜为基底的柔性 DSCs. 这一类 型的 DSCs 具备了质轻, 可弯曲, 抗冲击能力强, 可 塑性好等优点, 成为目前国内外研究的新热点..$^{-10}$ 但是以带有导电膜的高分子聚苯二甲酸乙二醇酯 (ITO/PET)或聚䒬二甲酸乙二醇酯(ITO/PEN)为基底 的柔性 DSCs, 由于基底最高只能承受 $150^{\circ} \mathrm{C}$, 不能 像刚性 DSCs 那样通过高温焙烧 $\mathrm{TiO}_{2}$ 浆料制备多孔 高效的光阳极薄膜, 从而大大降低了柔性 DSCs 的 光电转化效率. 近年来很多研究小组开展了低温制 膜的研究. 其中 Iwasaki 研究组 ${ }^{11}$ 研究了不含有机粘 结剂的 $\mathrm{TiO}_{2}$ 浆料来低温制备阳极薄膜, 但该法制备 的柔性小面积 DSCs 的光电转化效率仅为 $2.6 \%$, Hagfeldt 等 ${ }^{12}$ 对柔性基底上的 $\mathrm{TiO}_{2}$ 薄膜施加压力, 研 究不同压力下电池各项光电参数的变化, 并在最优 条件下电池取得了 $3.0 \%$ 的光电转化效率. 清华大学 林红研究组 ${ }^{13}$ 通过研究 $\mathrm{TiO}_{2}$ 浆料的配方, 优化柔性 DSCs 的制作工艺, 使光电转化效率达到了 $4.05 \%$. 但总体来说低温制备的光阳极构建的电池光电转 化效率还不高.

本课题组 ${ }^{14}$ 自 2002 年开展柔性 DSCs 的研究, 开发了基于不锈钢板、镍板、铜板、铝板、聚酯薄膜 和导电塑料基板的 6 种柔性 DSCs 对电极. 最近我们 又开发了一种简便的膜转移技术高温制备柔性光 阳极膜, 即在平滑的基板表面制备膜电极, 高温烧 结得到多孔的 $\mathrm{TiO}_{2}$ 膜, 通过简单的物理摩擦法将高 导电性的多孔膜转移到柔性基底上, 然后施加一定 压力, 取得了目前基于高分子导电膜基底的全柔性 DSCs 的最高光电转化效率 $(5.7 \%) .{ }^{15}$ 为了满足柔性 DSCs 产业化的需求, 众多研究者积极开展高效大面 积柔性电池的研究. 但是迄今为止世界上关于大面 积柔性 DSCs 的报道还很少, 特别是关于柔性 DSCs
的长期稳定性研究.

本文设计利用我们独自开发的喷涂法构建 2 $\mathrm{cm} \times 3 \mathrm{~cm}$ 和 $5 \mathrm{~cm} \times 7 \mathrm{~cm}$ 大面积全柔性 DSCs. 讨论散 射层、加压法及光照强度对 DSCs 光电性能的影响, 以期得到大幅度提高大面积全柔性 DSCs 的光电转 化效率的最优制作方法. 同时跟踪分析了电池的各 项性能参数的稳定性.

\section{2 实验部分}

\section{1 试剂与仪器}

所用试剂为 $\mathrm{TiO}_{2}$ 纳米粉体 (P25, 粒径 $25 \mathrm{~nm}$, $70 \%$ 锐钛矿相 $+30 \%$ 金红石相, Degussa, 德国)、 $\mathrm{TiO}_{2}$ 大粒子(ST41, 粒径 $160 \mathrm{~nm}, \mathrm{ISK}$, 日本)、钛酸四丁酯 (TBT, 分析纯, 天津科密欧化学试剂有限公司)、硼 氢化钠(分析纯, 上海国药集团)、氯铂酸(分析纯, 大 连辽东化学试剂公司)、钉染料(N719, 大连七色光)、 异丙醇(分析纯, 天津博迪化工股份有限公司)、低温 银浆料(BY9700, 上海宝银有限公司).

基底材料是铟掺杂的氧化锡/聚萗二甲酸乙二 醇酯(ITO/PEN, Peccell 公司, 日本); 利用全方位行 星式球磨机(QM-QX04, 南京大学仪器厂) 球磨 $\mathrm{TiO}_{2}$ 浆料; 实验室小型热压机(R3201, 武汉启恩科技有 限公司)用来对光阳极材料施加压力; 利用粗䊁度检 测仪(SNRFCOM130A, 东京精密, 日本)测定薄膜厚 度; 利用电化学工作站(ZAHNER ZENNIUM, 德国 Zahner 公司)研究电池内阻变化; 太阳光模拟器 (1 sun, 光强 $100 \mathrm{~mW} \cdot \mathrm{cm}^{-2}, \mathrm{AM} 1.5$, Oriel, 美国)和数字 源(Keithley-2601, 美国)用来测定柔性 DSCs 的光电 性能; $\mathrm{TiO}_{2}$ 薄膜的表面形貌由扫描电镜表征(Hitachi, S4800).

\section{2 柔性 $\mathrm{TiO}_{2}$ 光阳极膜的制备}

浆料的制备. 取 $4 \mathrm{~g} \mathrm{P} 25$ 或 ST41 粉体与适量 TBT 及异丙醇、一定量锆珠, 混合球磨 $4 \mathrm{~h}$. 普通低温 $\mathrm{TiO}_{2}$ 薄膜(A)的制备, 首先将 ITO/PEN 基板边缘用胶 带保护, 保留两块对称的 $0.9 \mathrm{~cm} \times 1.5 \mathrm{~cm}$ 面积的空 白, 将 P25 浆料均匀喷涂到基板空白处, $120{ }^{\circ} \mathrm{C}$ 干燥 $2 \mathrm{~h}$, 降至室温. 然后揭掉胶带, 在薄膜边缘处印刷低 温银浆料制备银梛电极, $120^{\circ} \mathrm{C}$ 干燥 $30 \mathrm{~min}$. 加散射 层 $\mathrm{TiO}_{2}$ 薄膜(B) 的制备是先喷涂适量的 $\mathrm{P} 25$ 浆料后 再喷涂少量的 ST4 1 大粒子浆料; 喷涂一定量 P25 浆 
料成膜后用实验室小型热压机在 $40{ }^{\circ} \mathrm{C}, 60 \mathrm{MPa}$ 下 加压 $1 \mathrm{~min}$, 得到加压后 $\mathrm{TiO}_{2}$ 膜 $(\mathrm{C})$, 其它实验步骤与 薄膜 $\mathrm{A}$ 的制备相同. 粗楉度检测仪测得三种光阳极 膜厚为 $(12 \pm 1) \mu \mathrm{m}$.

\section{3 柔性 Pt 对电极的制备}

化学还原方法制备 Pt 对电极, ${ }^{16}$ 将 $0.5 \%(w)$ 的氯 铂酸异丙醇溶液喷涂到 ITO/PEN 基板上, $120^{\circ} \mathrm{C}$ 干 燥 $1 \mathrm{~h}$, 冷至室温, 取出后快速浸入 $30 \mathrm{mmol} \cdot \mathrm{L}^{-1}$ $\mathrm{NaBH}_{4}$ 的水/乙醇溶液, 反应约 $3 \mathrm{~min}$ 取出, 依次用去 离子水、无水乙醇冲洗, 吹干, 最后 $120^{\circ} \mathrm{C}$ 烘干 $1 \mathrm{~h}$. 印刷银栅电极, 得到对电极.

\section{4 全柔性 DSCs 的组装及光电性能测试}

将 $\mathrm{TiO}_{2}$ 薄膜浸泡于 $5 \times 10^{-4} \mathrm{~mol} \cdot \mathrm{L}^{-1}$ 的 N719 的乙 醇溶液中 $16 \mathrm{~h}$, 制成光阳极. 将光阳极与对电极采用 三明治结构组装, 夹层为热熔 surlyn 膜, 然后灌注电 解液, 电解液由 $1.0 \mathrm{~mol} \cdot \mathrm{L}^{-1} 1$-甲基-3-丙基咪唑碘 $(\mathrm{PMII}) 、 0.15 \mathrm{~mol} \cdot \mathrm{L}^{-1}$ 碘单质 $\left(\mathrm{I}_{2}\right) 、 0.1 \mathrm{~mol} \cdot \mathrm{L}^{-1} \mathrm{GuSCN}$ 、 $0.5 \mathrm{~mol} \cdot \mathrm{L}^{-1}$ 叔丁基吡啶 (TBP) 及 3-甲氧基丙腈 $(\mathrm{MPN})$ 组成. 最后, 紫外胶固化封装. 对制作的 DSCs 在 $\mathrm{AM} 1.5$, 光照强度为 $100 \mathrm{~mW} \cdot \mathrm{cm}^{-2}$ 的模拟太阳光 照射下, 利用 Keithly 数字源表进行光电性能测试, 得出光电流密度-光电压 $(J-V)$ 关系曲线, 并测试其 在 $900 \mathrm{~h}$ 内的光电性能变化, 测试条件为自然光照 射, 测试时间为 2011年3-4月, 地点为中国大连. 另 外, 利用电化学工作站在暗态下, 施加 $-0.7 \mathrm{~V}$ 的偏 压测试电池内阻变化, 得到电化学阻抗谱图(EIS).

\section{3 结果与讨论}

\section{1 电池的光电性能}

利用简单机械加压法制备的小面积 $(0.4 \mathrm{~cm} \times$ $0.4 \mathrm{~cm})$ 柔性 DSCs 的光电转化效率 $(\eta)$ 高达 $5.50 \%$, 其中开路电压 $\left(V_{\mathrm{oc}}\right): 780 \mathrm{mV}$, 短路电流密度 $\left(J_{\mathrm{sc}}\right)$ : $10.81 \mathrm{~mA} \cdot \mathrm{cm}^{-2}$, 填充因子 $(\mathrm{FF}): 0.65$. 我们把实验用 的 DSCs 面积从 $0.16 \mathrm{~cm}^{2}$ 扩大到 $2.7 \mathrm{~cm}^{2}$. 图 1 为不同 方法处理后的光阳极组成 DSCs 的 $J-V$ 曲线, 光阳 极 A、B、C 组成的 DSCs 光电转化效率分别为

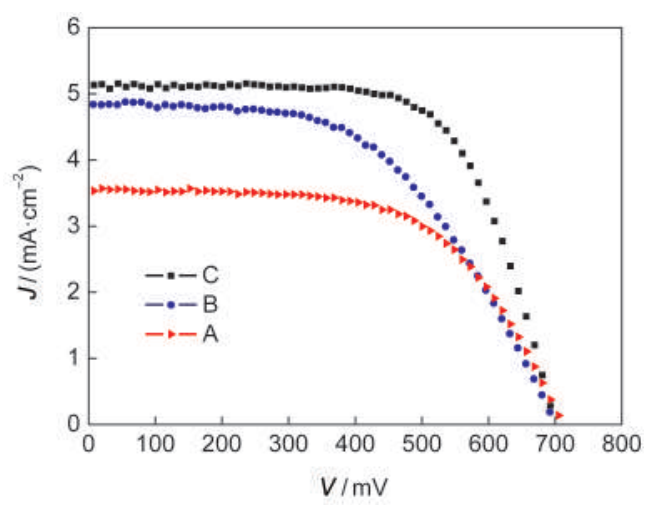

图 1 不同方法处理的光阳极组装的 DSCs 光电流密度一光电压 $(J-V)$ 曲线

Fig.1 Photocurrent density-photovoltage $(J-V)$ curves of the DSCs based on photoanodes treated with different methods

(A) normal, (B) with scatter layer, (C) with pressure

$1.52 \%, 1.81 \%, 2.50 \%$, 具体数值如表 1 . 明显看出, 大 面积 DSCs 光电转换效率明显小于小面积 DSCs, 这 主要归因于面积放大时基板电阻增大, 电子收集效 率降低, 电流密度减小. ${ }^{17}$ 与不经任何处理的光阳极 $\mathrm{A}$ 相比, 加散射层可以使电池的光电转化效率提高 $20.0 \%$, 加压法使光电转化效率提高 $66.7 \%$. 无论对 光阳极进行散射层处理还是加压处理, 电池的 $V_{\mathrm{oc}}$ 变 化不大. 散射层的引入使光电转化效率增大的原因 被认为是当光入射到半导体薄膜上遇到大粒子时, 光在粒子表面向各个方向发生散射, 增加了光在半 导体薄膜中的传播路程, 使吸附在薄膜上的染料对 未被充分利用的光进行二次利用, 从而提高了染料 分子光捕获效率, 特别是提高了染料分子对长波区 光的吸收效率, 增加了光电流的输出, ${ }^{18-20}$ 正如表 1 数据所示, $J_{\mathrm{sc}}$ 由 $3.57 \mathrm{~mA} \cdot \mathrm{cm}^{-2}$ 增加到 $4.81 \mathrm{~mA} \cdot \mathrm{cm}^{-2}$. 但是散射层的引入在一定程度上使薄膜的表面孔 径减小, 限制了电解质的扩散, 使 $\mathrm{FF}$ 从 0.60 下降至 0.54. 另一方面, 加压使 $\mathrm{TiO}_{2}$ 粒子之间以及 $\mathrm{TiO}_{2}$ 粒子 与基底材料之间结合得更加紧密, 这就使相同膜厚 条件下 $\mathrm{TiO}_{2}$ 粒子数增加, 有利于吸附更多的染料, 从而使光生载流子注入增多, 进而增加光电流, 这

表 1 不同光阳极组装的 DSCs 光电性能与电化学阻抗参数

Table 1 Photovoltaic and EIS parameters of the DSCs based on different photoanodes

\begin{tabular}{|c|c|c|c|c|c|c|c|}
\hline Photoanode & $V_{\mathrm{oc}} / \mathrm{mV}$ & $J_{\mathrm{sc}} /\left(\mathrm{mA} \cdot \mathrm{cm}^{-2}\right)$ & $\mathrm{FF}$ & $\eta / \%$ & $R_{\mathrm{s}} / \Omega$ & $R_{\mathrm{ct}}^{1} / \Omega$ & $R_{\mathrm{ct}}^{2} / \Omega$ \\
\hline $\mathrm{A}$ & 711 & 3.57 & 0.60 & 1.52 & 6.67 & 0.44 & 4.57 \\
\hline $\mathrm{B}$ & 704 & 4.81 & 0.54 & 1.81 & 6.31 & 0.78 & 6.20 \\
\hline $\mathrm{C}$ & 705 & 5.22 & 0.68 & 2.50 & 5.89 & 0.82 & 2.84 \\
\hline
\end{tabular}

$V_{\mathrm{oc}}$ : open circuit voltage, $J_{\mathrm{sc}}$ : short circuit current density, FF: fill factor, $\eta$ : energy conversion efficiency; $R_{\mathrm{s}}$ : series resistance,

$R_{\mathrm{ct}}^{1}$ c charge transfer resistance in Pt/electrolyte interface, $R_{\mathrm{cc}}^{2}$ : charge transfer resistance in the interface of $\mathrm{TiO}_{2} /$ dye/electrolyte 
与 $J-V$ 测试结果一致, 加压使 $J_{\mathrm{sc}}$ 由 $3.57 \mathrm{~mA} \cdot \mathrm{cm}^{-2}$ 增 加至 $5.22 \mathrm{~mA} \cdot \mathrm{cm}^{-2}$, 提高了 $46.2 \%$. 同时由于加压后 $\mathrm{TiO}_{2}$ 粒子之间以及 $\mathrm{TiO}_{2}$ 粒子与基底材料之间的结 合更加紧密, 电子传递更加通畅, 电池内部电阻减 小, ${ }^{21}$ 从而使 $\mathrm{FF}$ 从 0.60 上升至 0.68 , 提高了 $13.3 \%$. 电 流密度提高与填充因子增加的共同作用使光电转 化效率从 $1.52 \%$ 增加到 $2.50 \%$, 光电转化效率得到 $66.7 \%$ 的大幅度提高.

为了分析散射层及机械加压对 $\mathrm{TiO}_{2}$ 光阳极的 影响, 我们对用不同方法处理的 $\mathrm{TiO}_{2}$ 电极 $(\mathrm{A} 、 \mathrm{~B} 、 \mathrm{C})$ 组装的 DSCs 进行了电化学阻抗(EIS)测试. 图 2 是 典型的 Nyquist 阻抗图, 插图是 DSCs 的等效电路 图, ${ }^{22,23}$ 其中 $R_{\mathrm{s}}$ 代表整个回路的串联电阻(series resistance), $R_{\mathrm{ct}}^{1}$ 表示 $\mathrm{Pt} /$ 电解液界面间的传荷电阻, $\mathrm{CPE}^{1}$ 代 表相应的电容. $R_{\mathrm{ct}}^{2}$ 表示 $\mathrm{TiO}_{2} /$ 染料/电解液界面间的 传荷电阻, $\mathrm{CPE}^{2}$ 代表相应的电容, $Z_{\mathrm{N}}$ 为电解液中的 氧化还原电对 $\left(\mathrm{I}_{3}^{-} / \mathrm{I}^{-}\right)$的能斯特扩散电阻. 这里我们主 要考察光阳极材料对电池性能的影响, 即主要考察 $R_{\mathrm{s}}$ 与 $R_{\mathrm{ct}}^{2}$ 的变化. 表 1 中, 加散射层后, $R_{\mathrm{s}}$ 从 $6.67 \Omega$ 下 降到 $6.31 \Omega, R_{\mathrm{ct}}^{2}$ 则从 $4.57 \Omega$ 增加到 $6.20 \Omega$, 主要是因 为散射层大粒径 $\mathrm{TiO}_{2}$ 粒子堆积的薄膜, 大粒子的 $\mathrm{TiO}_{2}$ 一定程度上阻碍了 $\mathrm{I}_{3}^{-} / \mathrm{I}^{-}$在阳极薄膜扩散及渗 透. 但大粒径 $\mathrm{TiO}_{2}$ 粒子容易产生光漫反射提高光的 利用率, 电池光电转化效率从 $1.52 \%$ 上升至 $1.81 \%$ 是 光的充分利用及电池内部电阻变化共同作用的结 果. 另一方面, 从图 3 的 SEM 图中可看出加压后整 个薄膜变得更加致密, $\mathrm{TiO}_{2}$ 粒子间粘结得更加牢固. 这表明加压后电子在 $\mathrm{TiO}_{2}$ 粒子间及 $\mathrm{TiO}_{2}$ 粒子与

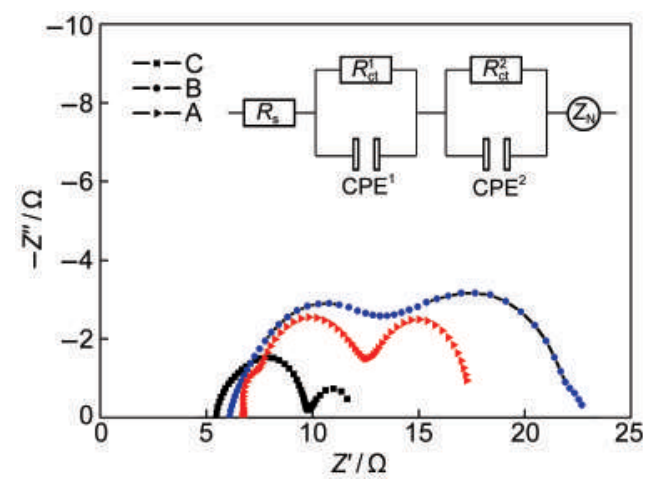

图 2 不同光阳极组装的 DSCs 电化学阻抗谱

Fig.2 Electrochemical impedance spectra (Nyquist) of the DSCs based on different photoanodes

(A) normal, (B) with scatter layer, (C) with pressure; The inset is the equivalent circuit diagram of the DSCs. CPE ${ }^{1}$ : the capacitance in the interface of Pt/electrolyte; $\mathrm{CPE}^{2}$ : the capacitance in the interface of $\mathrm{TiO}_{2} /$ dye/electrolyte, $Z_{\mathrm{N}}$ : Nernst diffusion impedance
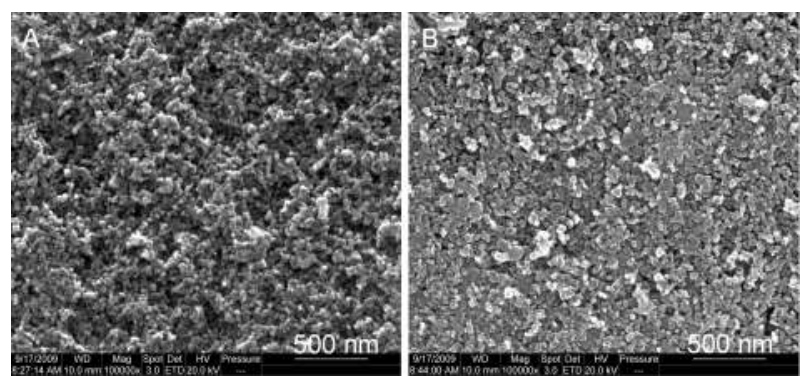

图 3 加压前(A)后(B) $\mathrm{TiO}_{2}$ 薄膜扫描电镜图

Fig.3 SEM images of the $\mathrm{TiO}_{2}$ films before (A) and after (B) pressure

ITO-PEN 导电基板间传递更快, 使 $\mathrm{TiO}_{2}$ 导带中的电 子更容易到达 ITO-PEN 导电基板, 减少了电子的复 合几率. ${ }^{24}$ 加压后 $R_{\mathrm{s}}$ 从 $6.67 \Omega$ 下降至 $5.89 \Omega, R_{\mathrm{ct}}^{2}$ 从 $4.57 \Omega$ 下降至 $2.84 \Omega$.

\section{2 电池的稳定性}

电池的稳定性是制约 DSCs 产业化的主要因素 之一, 因此我们进行了长达 $900 \mathrm{~h}$ 的稳定性实验. 如 图 4 所示, 光电流密度先降低后升高, 一周后稳定在 $5 \mathrm{~mA} \cdot \mathrm{cm}^{-2}$; 电压在 690-730 $\mathrm{mV}$ 之间变化, 经过 $900 \mathrm{~h}$, 没有明显衰减; 填充因子在第一周内持续增
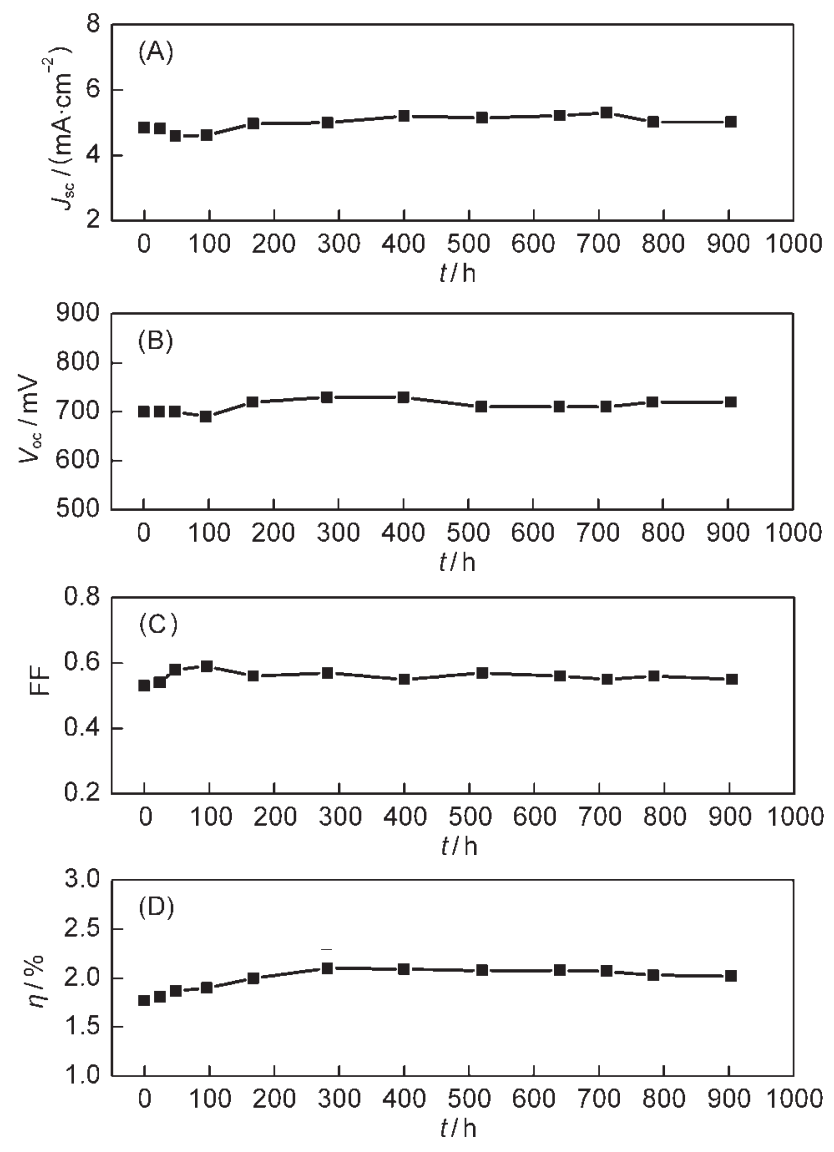

图 4 DSCs 稳定性实验光电性能参数

Fig.4 Photovoltaic parameters of the DSCs in the stability tests 
加, 这是由于较大的电池面积导致电解液的扩散需 要一定的时间, 待电解液充分扩散后, 填充因子达 到最大值, 维持在 0.57 左右. 电池的光电转化效率 持续增加, $288 \mathrm{~h}$ 后增加至最大值 $2.1 \%$, 最后稳定在 $2.0 \%$ 左右. 以上研究结果表明制备的柔性 DSCs 具 有很好的稳定性, 这一结果与目前 Miyasaka 组 ${ }^{25}$ 报 道的可保持 $220 \mathrm{~h}$ 内光电性能不变的结果相比得到 了大幅改善.

\section{3 电池面积的再扩大及光照强度对电池光电性 能的影响}

柔性 DSCs 的最大特点就是可塑性强, 特别适 合在室内低光照条件下使用. 众所周知, 硅电池在 低光强下光电转化效率急剧下降, 而 DSCs 则恰恰 相反, 低光照条件下其光电转化效率有明显提高. 由于活性面积为 $2.7 \mathrm{~cm}^{2}$ 的 DSCs 输出功率为 6.8 $\mathrm{mW}$, 还不能满足日常需要, 所以我们进一步把 DSCs 面积扩大 6 倍至 $16.2 \mathrm{~cm}^{2}$. 图 5 所示的是活性 面积为 $16.2 \mathrm{~cm}^{2}$ 的 DSC 在不同光强下的 $J-V$ 曲线. 在标准条件下 $\left(1 \mathrm{sun}\right.$, 光强 $\left.100 \mathrm{~mW} \cdot \mathrm{cm}^{-2}\right)$, 电池光电 性能参数为 $V_{\mathrm{oc}}=640 \mathrm{mV}, J_{\mathrm{sc}}=3.30 \mathrm{~mA} \cdot \mathrm{cm}^{-2}, \mathrm{FF}=0.53$, $\eta=1.12 \%$; 在 0.8 sun 条件下, $V_{\mathrm{oc}}=660 \mathrm{mV}, J_{\mathrm{sc}}=2.76$ $\mathrm{mA} \cdot \mathrm{cm}^{-2}, \mathrm{FF}=0.55, \eta=1.25 \%$; 在 0.6 sun 条件下, $V_{\mathrm{oc}}=$ $670 \mathrm{mV}, J_{\mathrm{sc}}=2.26 \mathrm{~mA} \cdot \mathrm{cm}^{-2}, \mathrm{FF}=0.57, \eta=1.44 \%$; 在 $0.4 \mathrm{sun}$ 条件下, $V_{\mathrm{oc}}=650 \mathrm{mV}, J_{\mathrm{sc}}=1.59 \mathrm{~mA} \cdot \mathrm{cm}^{-2}, \mathrm{FF}=$ $0.62, \eta=1.60 \%$. 以上数据表明: 光照强度的减小导致 电池电流密度降低, 而填充因子和光电转化效率则 逐渐增大. 由于 DSCs 光电转化效率指的是在外部 回路上连接最佳负荷阻抗时得到的最大功率 $\left(P_{\text {max }}\right)$ 与入射光强 $\left(P_{\mathrm{in}}\right)$ 之比. ${ }^{26}$ 所以, 在低光强下, DSCs 的 光电转化效率增加, 这也是 DSCs 相比传统硅电池

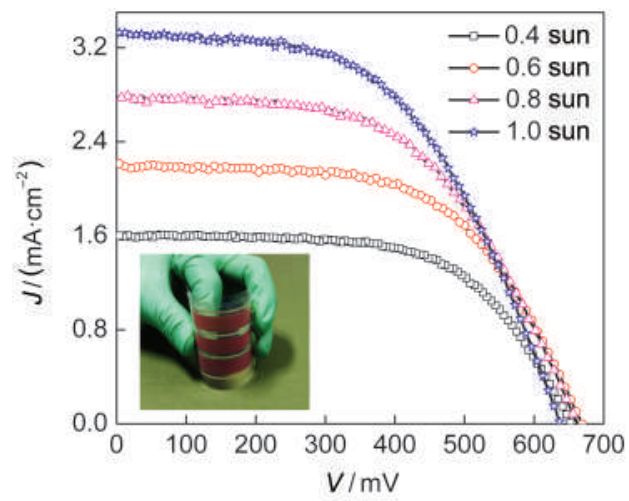

图 $516.2 \mathrm{~cm}^{2}$ 面积 $\mathrm{DSC}$ 在不同光照强度下 $J-V$ 曲线

Fig.5 $J-V$ curves of the DSC with an active area of $16.2 \mathbf{~ c m}^{2}$ under different light intensities The inset is the photograph of the larger scaled DSC.
的最重要的优势之一.

\section{4 结 论}

综上所述, 我们成功地制备了全柔性大面积 DSCs, 有效面积为 $2.7 \mathrm{~cm}^{2}$ 的 DSCs 光电转化效率达 到了 $2.50 \%$. 有效面积为 $16.2 \mathrm{~cm}^{2}$ 的 DSCs, 光电转化 效率达到 $1.60 \% . J-V$ 及 EIS 测试结果表明, 引入散 射层增加光的利用率, 使光电转化效率提高了 $20 \%$, 加压法解决了低温制备 $\mathrm{TiO}_{2}$ 粒子与粒子之间 及粒子与基底之间粘结不好导电性低的弊端, 使电 池的光电转化效率大幅度提高了 $66.7 \%$. 长期稳定 性实验结果表明, 制作的柔性 DSCs 在 $900 \mathrm{~h}$ 后未发 生光电性能的降低. 总之, 这些研究结果为柔性染 料敏化太阳能电池的基础研究和大面积产业化技 术应用研究奠定了基础.

\section{References}

(1) O'Regan, B.; Grätzel, M. Nature 1991, 353, 737.

(2) Grätzel, M. Nature 2001, 414, 338.

(3) Tao, L.; Yang, Y. Z.; Shi, C. W.; Wu, Y. C.; Wu, X. Y. Acto Phys. -Chim. Sin. 2010, 26, 578. [桃 李, 杨燕珍, 史成武, 吴玉程, 吴小燕. 物理化学学报, 2010, 26, 578.]

(4) Li, B.; Cheng, P.; Deng, C. S. Chin. J. Chem. 2007, 20, 816.

(5) Hagfeldt, A.; Boschloo, G.; Sun, L. C.; Kloo, L.; Pettersson, H. Chem. Rev. 2010, 110, 6595.

(6) Pichot, F.; Pitts, J. R.; Gregg, B. A. Langmuir 2000, 16, 5626.

(7) Chen, D. H.; Huang, F. Z.; Cheng, Y. B.; Caruso, R. A. Adv. Mater. 2009, 21, 2206.

(8) Wang, Y.; Wu, J. H.; Fan, L. Q.; Lan, Z.; Xiao, Y. M.; Li, Q. H.; Huang, M. L. Mater. Rev. 2010, 24, 131. [王 岳, 吴季怀, 范 乐庆, 兰 章, 肖尧明, 李清华, 黄妙良. 材料导报, 2010, 24, 131.]

(9) Wang, M. K.; Anghel, A. M.; Marsan, B.; Ha, N. C.; Pootrakulchote, N.; Zakeeruddin, S. M.; Grätzel, M. J. Am. Chem. Soc. 2009, 131, 15976

(10) Yang, L.; Xin, G.; Wu, L. Q.; Ma, T. L. Prog. Chem. 2009, 21 , 2242. [杨 丽, 辛 刚, 吴丽琼, 马廷丽. 化学进展, 2009, 21, 2242.]

(11) Iwasaki, M.; Lee, C. W.; Kim, T. H.; Park, W. K. J. Ceram. Soc Jpn. 2008, 116, 153.

(12) Lindström, H.; Holmberg, A.; Magnusson, E.; Lindquist, S. E.; Malmqvist, L.; Hagfeldt, A. Nano Lett. 2001, 1, 97.

(13) Lin, H.; Li, X.; Liu, Y. Z.; Li, J. B. Mater. Sci. Eng. B 2009, 161, 2.

(14) Ma, T. L.; Fang, X. M.; Akiyama, M.; Inoue, K.; Nomam, H.; Abe, E. J. Electroanal. Chem. 2004, 574, 77.

(15) Yang, L.; Wu, L. Q.; Wu, M. X.; Xin, G.; Lin, H.; Ma, T. L. Electrochem. Commun. 2010, 12, 1000 
(16) Papageorgiou, N.; Maier, W. F.; Grätzel, M. J. Electrochem. Soc. 1997, 144, 876.

(17) Han, L.; Koide, N.; Chiba, Y.; Islam, A.; Komiya, R.; Fuke, N.; Fukui, A.; Yamanaka, R. Appl. Phys. Lett. 2005, 86, 21350.

(18) Usami, A. Sol. Energy Mater. Sol. Cells 2000, 64, 73.

(19) Huang, F. Z.; Chen, D. H.; Zhang, X. L.; Caruso, R. A.; Cheng, Y. B. Adv. Funct. Mater. 2010, 20, 1301.

(20) Liu, J.; Yang, H. T.; Zhang, J. B.; Zhou, X. W.; Lin, Y. Acta Phys. -Chim. Sin. 2011, 27, 408. [刘 佳, 杨浩田, 张敬波, 周晓文, 林 原. 物理化学学报, 2011, 27, 408.]

(21) Koide, N.; Islam, A.; Chiba, Y.; Han, L. Y. J. Photochem.
Photobiol. A: Chem. 2006, 182, 296.

(22) Kern, R.; Sastrawan, R.; Ferber, J.; Stangl, R.; Luther, J. Electrochim. Acta 2002, 47, 4213.

(23) Wang, Q.; Moser, J. E.; Grätzel, M. J. Phys. Chem. B 2005, 109, 14945.

(24) Green, A. N. M.; Palomares, E.; Haque, S. A.; Kroon, J. M.; Durrant, J. R. J. Phys. Chem. B 2005, 109, 12525.

(25) Ikegami, M.; Suzuki, J.; Teshima, K.; Kawaraya, M.; Miyasaka, T. Sol. Energy Mater. Sol. Cells 2009, 93, 836.

(26) Trupke, T.; Würfel, P.; Uhlendorf, I. J. Phys. Chem. B 2000, 104, 11484.

\section{欢迎订阅《物理化学学报》}

2012年全国报刊杂志征订工作已经开始,敬请向贵单位推荐订阅 2012年《物理化学学报》.

《物理化学学报》是由中国科协主管, 中国化学会主办, 北京大学化学与分子工程学院承办的基础学科类学术 刊物.《物理化学学报》设有“通讯”、“研究论文”和“综述”等栏目, 报导物理化学学科及交叉学科的基础研究及应 用基础研究所取得的创新成果.

中国科学院院士唐有祺先生担任主编; 编委会中有 15 位中国科学院院士, 12 位海外学者. 2004 年, 《物理化学 学报》获得国内期刊界最高奖——第三届国家期刊奖百种重点期刊奖. 国家自然科学基金委重点学术期刊和中国 科协精品科技期刊工程项目资助出版. 读者普遍认为《物理化学学报》具有极高的学术价值和收藏价值.

《物理化学学报》已被美国《科学引文索引》(SCI)网络版、美国《化学文献》(CA)、日本《科技文献速报》、俄罗斯 《文献杂志》(AJ)、中国科协和国家自然基金委主办的《中国学术期刊文摘》、中国科学技术部万方数据网络中心的 《中国科技论文与引文数据库(CSTPCD)》、中国科学院文献情报中心的《中国科学引文数据库》、中国生物学文献 数据中心的《中国生物文摘》等国内外多种著名检索刊物和文献数据库摘引和收录.

《物理化学学报》现为月刊, 大 16 开本, 232 页, 亚光铜版纸印刷. 2012 年订价 35.00 元/册, 全年订价 420.00 元. 国内邮发代号 82-163, 欢迎国内读者到当地邮局订阅, 国外读者可通过中国国际图书贸易总公司订阅 (Code No 1443-MO). 若通过邮局订阅有困难或错过订阅, 请直接与编辑部联系.

欢迎广大科技工作者、科研单位、高等院校、图书馆订阅.

通讯地址: 北京大学化学楼 $\mathrm{C} 206$ 《物理化学学报》编辑部 邮 编: 100871

服务热线: +86-10-62751724

E-mail: whxb@pku.edu.cn

\section{传真: +86-10-62756388}

网址: http://www.whxb.pku.edu.cn/ 